\title{
Influence of Repeated Variable Load on Long-Term Behavior of Concrete Elements
}

\author{
Toni Arangjelovski ${ }^{1}$, Goran Markovski ${ }^{1}$ and Peter Mark ${ }^{2}$ \\ 1. Faculty of Civil Engineering, University St. Cyril and Methodius, Skopje 1000, Republic of Macedonia \\ 2. Institute of Concrete Structures, Ruhr-University Bochum, Bochum 44780, Germany
}

\begin{abstract}
The objective of this paper is to study the influence of repeated variable action on long-term behavior of concrete structural elements using quasi-permanent combination of actions, for the assessment of long-term effects (e.g., effects due to creep and shrinkage in concrete structures), as it is proposed in Eurocodes. Extensive experimental program and analytical research using model B3 and AAEM (age adjusted effective modulus) method was performed in order to define quasi-permanent factor $\psi_{2}$ for two specific loading histories. These loading histories were consist of long-term permanent action "G" and repeated variable action "Q". The variable load was applied in cycles of loading/unloading for $24 \mathrm{~h}$ and $48 \mathrm{~h}$ in period of 400 days appropriately for one series of concrete elements. 24 reinforced concrete beams, dimensions $150 \mathrm{~mm} \times 280 \mathrm{~mm} \times 3,000 \mathrm{~mm}$, were tested. Twelve beams were made of concrete class $\mathrm{C} 30 / 37$ and 12 of concrete class $\mathrm{C} 60 / 75$.
\end{abstract}

Key words: Repeated variable actions, autogenous shrinkage, creep, Model B3.

\section{Introduction}

Degradation of concrete structures is usually medium to long-term process that has great influence on structure's working life [1]. Among specific common causes responsible for structural degradation, action of repeated variable loads (cyclic loads) is especially important issue for the assessment of long-term effects (e.g., effects due to creep and shrinkage in concrete structures).

Variable actions (imposed load) are of great importance for certain concrete structures such as: storage areas at warehouses, traffic areas at parking garages (Fig. 1) and bridges under severe traffic conditions (Fig. 2).

Repeated variable actions cause significant increase in concrete and reinforcement strain, increase in crack width and deflections, reduction of the tension stiffening and increase in bond-slip [2].

The long-term effects due to creep and shrinkage

Corresponding author: Toni Arangjelovski, Ph.D., docent, research fields: concrete and prestressed structures. E-mail: arangelovskitoni@gf.ukim.edu.mk. under repeated variable actions could overcome serviceability limit state criteria of concrete structure.

According to Eurocodes EN 1990-EN 1999, in serviceability limit design, assessment of effects due to creep and shrinkage of concrete caused by repeated variable load are taken into consideration using quasi-permanent combination of actions (also used for reversible limit states). The level of quasi-permanent load was defined by the quasi-permanent factor $\psi_{2}$.

Recommended values of $\psi_{2}$ factor for different types of concrete structures are given in Tables 1 and 2, according to EN 1990:2002 [3].

In DIN report 102 "Concrete bridges" basing on Eurocodes for city bridges $\psi_{2}$ is assumed to 0.2 [4] and in the national application document of Finland for EN $1992-2 \psi_{2}=0.3[5]$.

The recommended value of $\psi_{2}$ factor, in Eurocode EN 1990, for railway bridges is equal to zero. But if deformation is considered for persistent and transient design situations, $\psi_{2}$ should be taken equal to 1.00 for rail traffic actions (according to Table A2.3 of EN 1990:2002) [3]. 


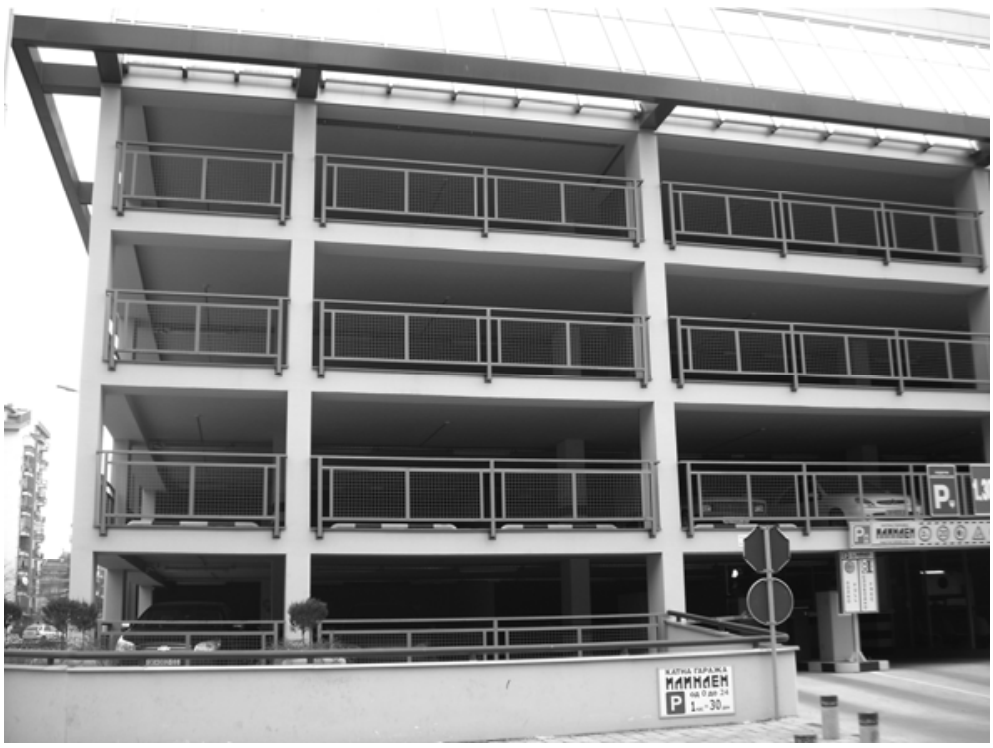

Fig. 1 Parking garage “Biser”, Skopje, Republic of Macedonia.

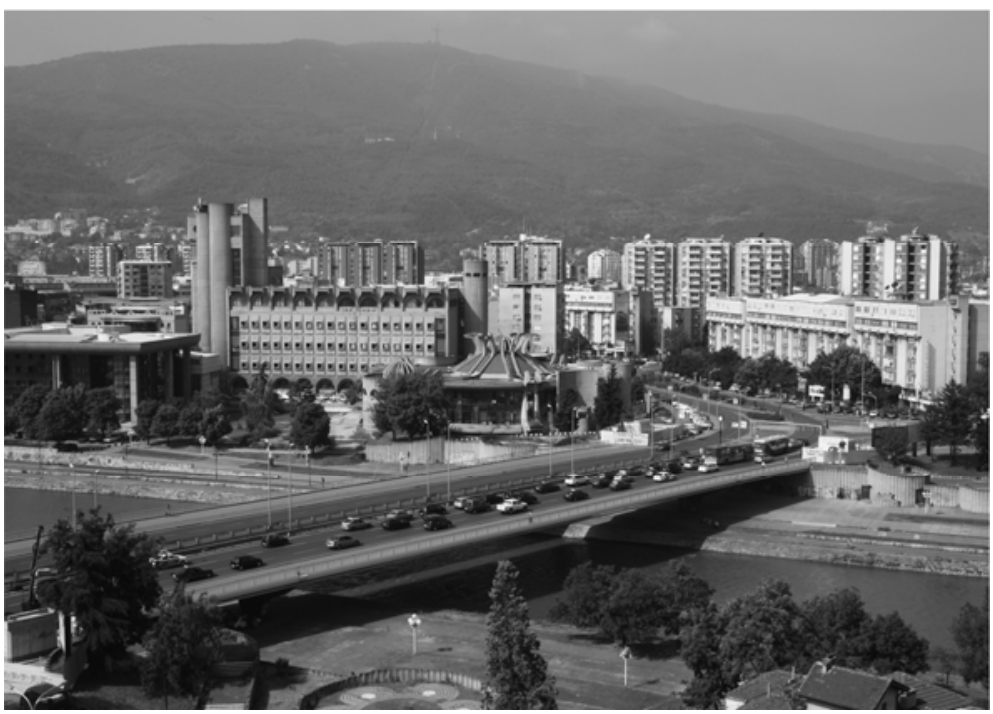

Fig. 2 City bridge “Goce Delcev”, Skopje, Republic of Macedonia.

Table 1 Recommended values of $\psi_{2}$ factor for buildings (Table A1.1 of EN 1990:2002) [3].

\begin{tabular}{ll}
\hline $\begin{array}{l}\text { Action (Imposed loads in buildings, } \\
\text { category (see EN1991-1-1)) }\end{array}$ & $\psi_{2}$ \\
\hline Category A: domestic, residential areas & 0.3 \\
Category B: office areas & 0.3 \\
Category C: congregation areas & 0.6 \\
Category D: shopping areas & 0.6 \\
Category E: storage areas & 0.8 \\
Category F: traffic area, & 0.6 \\
vehicle weight $\leq 30 \mathrm{kN}$ & \\
Category G: traffic area, & 0.3 \\
30 kN < vehicle weight $\leq 160 \mathrm{kN}$ & 0.0 \\
Category H: roofs & \\
\hline
\end{tabular}

Table 2 Recommended values of $\psi_{2}$ factor for road bridges (Table A2.1 of EN1990) [3].

\begin{tabular}{lll}
\hline Action & Symbol & $\psi_{2}$ \\
\hline & gr1a (LM1 + pedestrian or & 0.0 \\
& cycle-track loads) & \\
& gr1b (Single axle) & 0.0 \\
Traffic loads (see & gr2 (Horizontal forces) & 0.0 \\
EN1991-2, Table 4.4) & gr3 (Pedestrian loads & 0.0 \\
& gr4 (LM4-Crowd loading) & 0.0 \\
& gr5 (LM3-Special vehicles) & 0.0 \\
\hline
\end{tabular}

Note: For example, a value of $\psi_{2}$ other than zero may be envisaged for the UDL system of LM1 only, for bridges supporting severe continuous traffic. 
The factor $\psi_{2}$ is defined as a nationally determined parameter and a value could be proposed in the National annex to Eurocode EN 1990. This gives opportunity for research of effects of variable load and its replacement by a quasi-permanent load by the factor of participation $\psi_{2}$.

Extensive experimental program and analytical research using model B3 and AAEM (age adjusted effective modulus) method was performed in order to define factor $\psi_{2}$ for two specific loading histories. In this research, besides loading histories, one parameter more, strength of concrete was included in the analysis. Two types of concrete were analyzed: ordinary concrete with a strength class $\mathrm{C} 30 / 37$ and high-strength concrete of class C60/75.

In the experimental test of reinforced concrete beams, deflections, crack width and strains in concrete and reinforcement were measured. In this paper, the results from measured deflections are analyzed to propose factor $\psi_{2}$ for quasi-permanent combination of actions to verify criteria requirements for the control of deflection in serviceability limit state.

\section{Experimental Program}

\subsection{Description}

An experimental program was proposed to analyze the long-term behavior of reinforced concrete elements under action of different types of loading histories. The following loading histories were defined [6]:

- Short-term load to failure at concrete ages of 40 and 400 days for the series of beams "A" and "F";

- Long-term permanent load "G" that do not cause appearance of cracking in period of 400 days for the series of beams " $\mathrm{B}$ ";

- Long-term load with intensity equal to the sum of permanent load "G" and variable load "Q/2", i.e., $50 \%$ participation of the variable load acts as quasi-permanent load $\left(\psi_{2}=0.50\right)$. This sustained load " $\mathrm{G}+\mathrm{Q} / 2$ " was applied for a period of 400 days for the series of beams "C";

- Combination of action of long-term permanent load with intensity "G" and repeated variable load "Q" which was applied in cycles of loading/unloading for 24 hours. This load " $\mathrm{G} \pm \mathrm{Q}$ " was acting on the beam for a period of 400 days for the series of beams " $D$ ".

- Combination of action of long-term permanent load with intensity "G" and repeated variable load "Q" which was applied in cycles of loading/unloading for 48 hours. This load " $\mathrm{G} \pm \mathrm{Q}$ " was acting on the beam for a period of 400 days for the series of beams "D". The experimental program is given in Table 3.

For the tests, 24 reinforced concrete beams were used with dimensions $150 \mathrm{~mm} \times 280 \mathrm{~mm} \times 3,000 \mathrm{~mm}$. Of the total number, 12 beams were made of concrete class $\mathrm{C} 30 / 37$ and 12 beams were made of concrete class C60/75. Deformed reinforcement with yield strength of $400 \mathrm{MPa}$ was used. The long-term loads on the beams were applied by gravity lever which enable maximum increase of the applied load for 28 times. For the needs of the experiment, a correction of the gravity levers was made providing increase of 16.8 times of the initial load in order to obtain necessary test loads (Fig. 3). The dimensions of the concrete beams as well as details of reinforcement and test set up are given in Fig. 4.

Following measuring points were defined (Fig. 4): 20 points for measuring of strains at four different

Table 3 Experimental program.

\begin{tabular}{lll}
\hline Series of beams & Type of load & Loading cycle \\
\hline A & Short-term load & At 40 days \\
B & Permanent load "G" & 400 days \\
C & Permanent load "G" and quasi-permanent load "Q $/ 2$ " & $\mathrm{G}+\psi_{2} \mathrm{Q}=\mathrm{G}+0.5 \mathrm{Q}$ \\
$\mathrm{D}$ & Permanent load "G" and variable load "Q" & Loading/unloading for $\Delta t_{l}=24 \mathrm{~h}$ \\
E & Permanent load "G" and variable load "Q" & Loading/unloading for $\Delta t_{2}=48 \mathrm{~h}$ \\
F & Short-term load & At 400 days \\
\hline
\end{tabular}




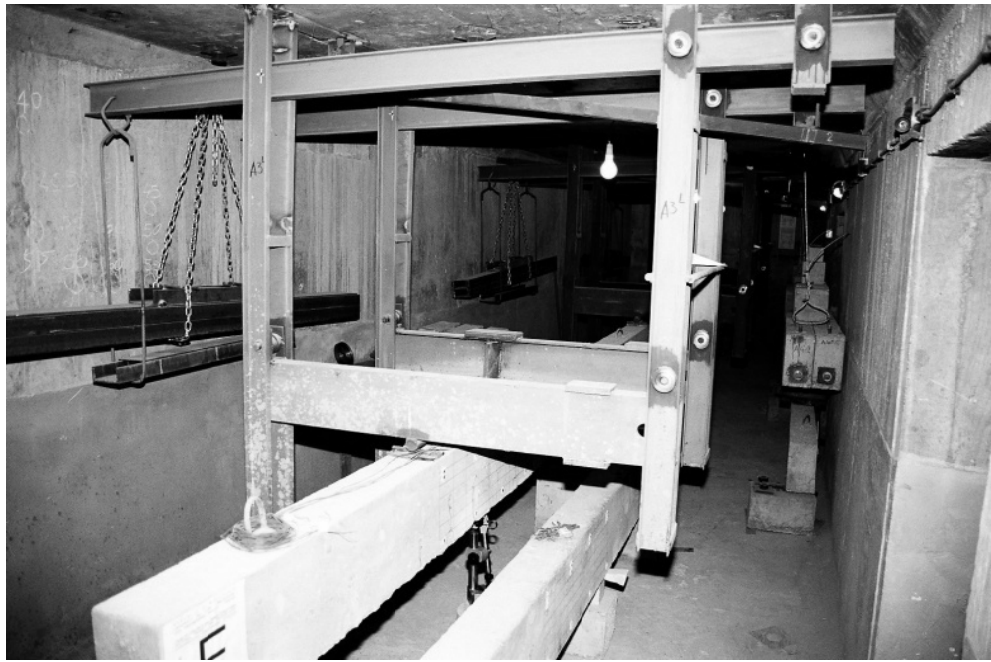

Fig. 3 Gravity lever in the laboratory for long-term behavior of concrete.
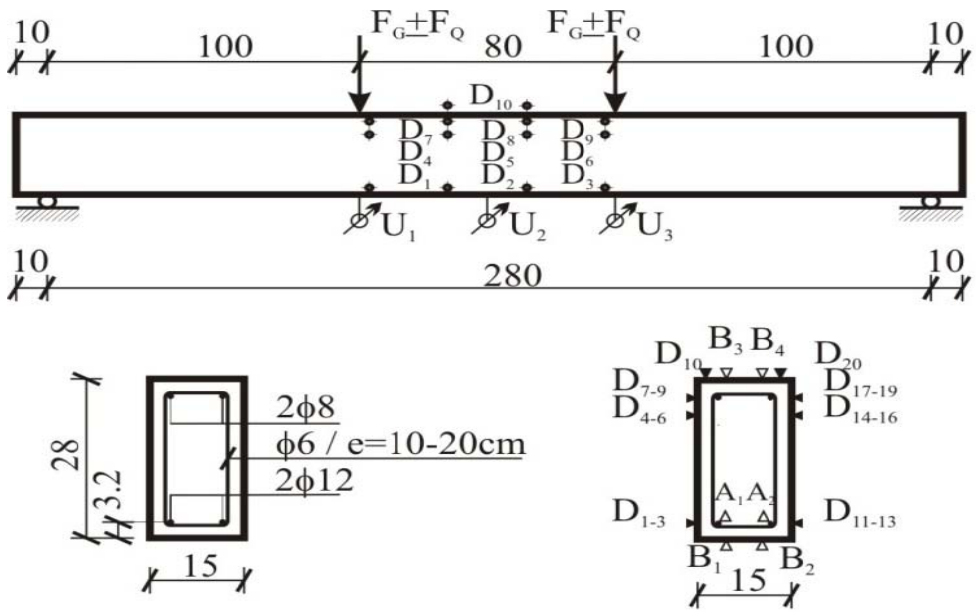

*D-mechanical deformeter, A-strain gauge for reinforcement, B-strain gauge for concrete, U-deflection-meter

Fig. 4 Reinforced concrete beams, dimensions, details of reinforcement and test set up.

levels along section height (at tensile reinforcement, at approximately neutral axis, at compression reinforcement and at upper edge of concrete section); long-term deflection in the middle of the span of beams and appearance and crack width.

Design characteristics of actions are given in Table 4. The value of permanent action was determined on the basis that no cracks will occurred when the beams were subjected to this load. The value of variable load was determined to obtain the ultimate load according to geometric properties of the beam and reinforcement ratio.

The tests were performed out in the Laboratory of Faculty of Civil Engineering in Skopje (Fig. 3) in environment of relative constant value of humidity $R H$ $=63 \%$ and temperature $T=17^{\circ} \mathrm{C}$.

\subsection{Mix Proportioning of Concrete}

For the concrete classes $\mathrm{C} 30 / 37$ and $\mathrm{C} 60 / 75 \mathrm{mix}$ proportioning of the concrete and initial testing were made to determine concrete quality of the following properties: property of fresh concrete including workability, density and initial setting time of concrete-(needed for test of autogenous shrinkage).

Mix proportioning of the concrete for strength class C30/37 and C60/75 are given in Table 5 . 
Table 4 Design values of actions.

\begin{tabular}{lll}
\hline Actions & Abbreviation & Intensity $(\mathrm{kN})$ \\
\hline Permanent action & "G" & $2 \times 4$ \\
Variable action & "Q" & $2 \times 7.6$ \\
Service load & "G+Q" & $2 \times 11.6$ \\
\hline
\end{tabular}

Table 5 Mix proportioning of concrete class C30/37 and C60/75.

\begin{tabular}{llll}
\hline Component & Type & $\begin{array}{l}\mathrm{C} 30 / 37 \\
\left(\mathrm{~kg} / \mathrm{m}^{3}\right)\end{array}$ & $\begin{array}{l}\mathrm{C} 60 / 75 \\
\left(\mathrm{~kg} / \mathrm{m}^{3}\right)\end{array}$ \\
\hline Cement & CEM I 42.5N & 360 & 414 \\
Mineral admixtures & Silica fume 8\% & - & 36 \\
Water & & 210 & 158 \\
Water-cement ratio & & 0.58 & 0.35 \\
Chemical admixtures & Superplasticizer 1.1\% & - & 5 \\
Aggregate & & 1,850 & 1,870 \\
I (0-4) mm & River sand & $40 \%$ & $37 \%$ \\
II (4-8) mm & Crushed limestone & $22 \%$ & $25 \%$ \\
III (8-16) mm & Crushed limestone & $38 \%$ & $38 \%$ \\
\hline
\end{tabular}

\section{Experimental Results}

\subsection{Properties of Concrete}

Results of material properties of concrete classes C30/37 and C60/75 are given in Tables 6 and 7. Mechanical properties of reinforcement are given in Table 8. Mechanical and deformation properties of the concrete were obtained on the following control specimens: for compressive strength on cube $150 \mathrm{~mm} \times$ $150 \mathrm{~mm} \times 150 \mathrm{~mm}$ and cylinder $\mathrm{D} / \mathrm{H}=150 \mathrm{~mm} \times 300$ $\mathrm{mm}$, flexural tensile strength on prisms $100 \mathrm{~mm} \times 100$ $\mathrm{mm} \times 400 \mathrm{~mm}$, splitting tensile strength on cube $150 \mathrm{~mm}$ $\times 150 \mathrm{~mm} \times 150 \mathrm{~mm}$, modulus of elasticity on cylinder $\mathrm{D} / \mathrm{H}=150 \mathrm{~mm} \times 300 \mathrm{~mm}$, autogenous shrinkage on prisms $100 \mathrm{~mm} \times 100 \mathrm{~mm} \times 500 \mathrm{~mm}$, drying shrinkage and creep on prisms $100 \mathrm{~mm} \times 100 \mathrm{~mm} \times 400 \mathrm{~mm}$.

Table 6 Properties of concrete class C30/37.

\begin{tabular}{lllll}
\hline Property of concrete & & & & \multicolumn{2}{c}{ C30/37 } \\
\cline { 4 - 5 } & & $\mathrm{MPa}$ & 39.7 & $t=400$ days \\
\hline Compressive strength & $f_{c k, c u b e}$ & $\mathrm{MPa}$ & 31.9 & 43.9 \\
Compressive strength & $f_{c k, c y l}$ & $\mathrm{MPa}$ & 5.7 & 34.1 \\
Flexural tensile strength & $f_{c t, f l}$ & $\mathrm{MPa}$ & 2.9 & 6.1 \\
Splitting tensile strength & $f_{c t, s p}$ & $\mathrm{MPa}$ & $30,483.2$ & 3.5 \\
Modulus of elasticity & $E_{c m}$ & $10^{-3}(\%)$ & 0.0431 & $33,149.6$ \\
Autogenous shrinkage strain & $\varepsilon_{a c}$ & $10^{-3}(\%)$ & 0.1124 & 0.1125 \\
Drying shrinkage strain & $\varepsilon_{c d}$ & $10^{-3}(\%)$ & 0.2845 & 0.5350 \\
Instantaneous strain & $\varepsilon_{e l}$ & $10^{-3}(\%)$ & - & - \\
Creep strain & $\varepsilon_{c c}$ & & - & 0.5140 \\
\hline Creep coefficient & $\varphi(400,40)$ & & 1.723 \\
\hline
\end{tabular}

Table 7 Properties of concrete class C60/75.

\begin{tabular}{lllll}
\hline Property of concrete & & & \multicolumn{2}{c}{ C60/75 } \\
\cline { 4 - 5 } & & & $\mathrm{MPa}$ & \multicolumn{1}{c}{$t=400$ days } \\
\hline Compressive strength & $f_{c k, c u b e}$ & $\mathrm{MPa}$ & 66.4 & 95.8 \\
Compressive strength & $f_{c k, c y l}$ & $\mathrm{MPa}$ & 9.3 & 75.5 \\
Flexural tensile strength & $f_{c t, f l}$ & $\mathrm{MPa}$ & 5.3 & 9.3 \\
Splitting tensile strength & $f_{c t, s p}$ & $\mathrm{MPa}$ & $39,470.9$ & 5.3 \\
Modulus of elasticity & $E_{c m}$ & $10^{-3}(\%)$ & 0.1637 & $41,228.6$ \\
Autogenous shrinkage strain & $\varepsilon_{a c}$ & $10^{-3}(\%)$ & 0.2960 & 0.2637 \\
Drying shrinkage strain & $\varepsilon_{c d}$ & $10^{-3}(\%)$ & 0.2130 & 0.4193 \\
Instantaneous strain & $\varepsilon_{e l}$ & $10^{-3}(\%)$ & - & - \\
Creep strain & $\varepsilon_{c c}$ & & - & 0.1490 \\
\hline Creep coefficient & $\varphi_{(400,40)}$ & & 0.703 \\
\hline
\end{tabular}

Table 8 Mechanical properties of reinforcement.

\begin{tabular}{llllll}
\hline No. & Reinforcement class & Diameter $(\mathrm{mm})$ & $\begin{array}{l}\text { Yield strength } f_{0.2} \\
(\mathrm{MPa})\end{array}$ & $\begin{array}{l}\text { Tensile strength } f_{m} \\
(\mathrm{MPa})\end{array}$ & $\begin{array}{l}\text { Modulus of elasticity } \\
(\mathrm{MPa})\end{array}$ \\
\hline 1 & 400 & 8 & 562 & 660 & 200,000 \\
2 & 400 & 12 & 466 & 719 & 200,200 \\
\hline
\end{tabular}


The typical diagrams of the development of autogenous shrinkage, drying shrinkage and creep under constant stress of $10 \mathrm{MPa}$ are given in Figs. 5 and 6.

The testing of the concrete and reinforcement properties was carried out according to the current European-Eurocode standards. Testing of the autogenous shrinkage was done according to the procedure given by Japan Concrete Institute: test method for autogenous expansion of cement paste, mortar and concrete [7].

\subsection{Long-Term Deflections}

Influence of the permanent action and repeated

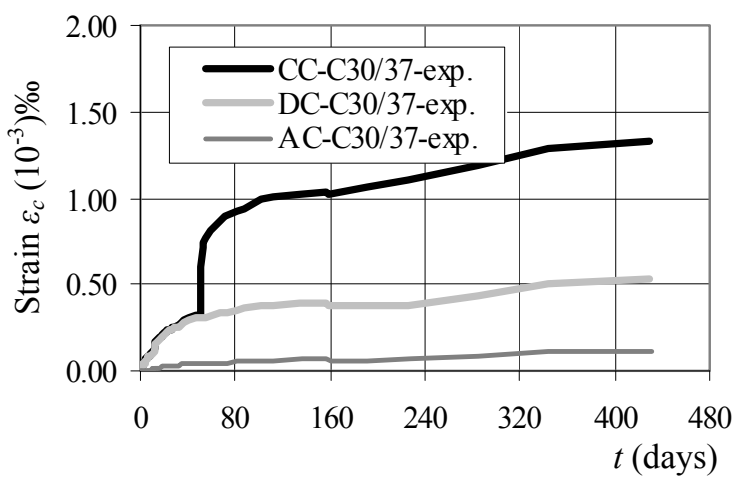

Fig. 5 Diagrams of autogenous shrinkage-time $\varepsilon_{a c}-t$, drying shrinkage-time $\varepsilon_{d c}-t$ and creep-time $\varepsilon_{c c}-t$ for concrete class C30/37. variable actions on long-term behavior of reinforced concrete beams was analyzed measuring the development of long-term deflections in period of 400 days.

Experimental results for the deflections within the beams series "D" and "E" are given in Section 4.2 Analytical analysis by the AAEM Method, by the relations of deflection (a)-time ( $t$ ) together with the results from the analytical analysis. The values of initial deflection, obtained at the moment of loading $t=$ 40 days and the final deflection measured at concrete age $t=400$ days for series " $\mathrm{D}$ " are given in Table 9, and for series "E" in Table 10.

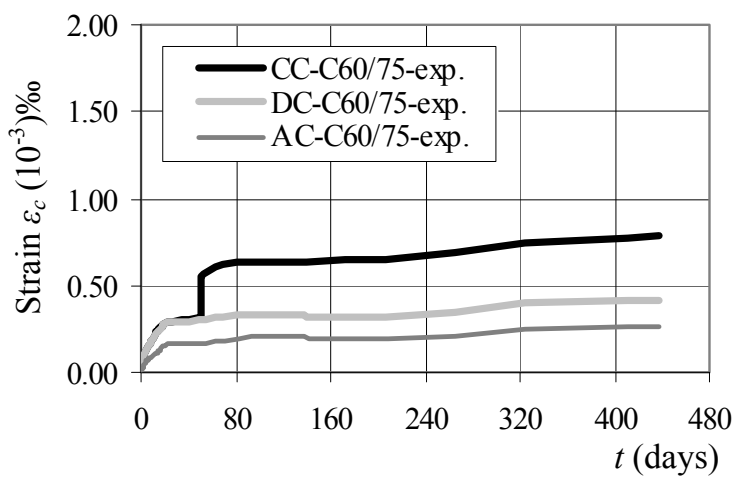

Fig. 6 Diagrams of autogenous shrinkage-time $\varepsilon_{a c}-t$, drying shrinkage-time $\varepsilon_{d c}$-t and creep-time $\varepsilon_{c c}$-t for concrete class C60/75.

Table 9 Experimentally measured deflections for series "D" beams.

\begin{tabular}{lllll}
\hline \multirow{2}{*}{ Level of actions } & \multicolumn{3}{c}{ Deflection $(\mathrm{mm})$} \\
\cline { 2 - 5 } & $\mathrm{D} 1-\mathrm{C} 30 / 37$ & $\mathrm{D} 2-\mathrm{C} 30 / 37$ & $\mathrm{D} 3-\mathrm{C} 60 / 75$ & D4-C60/75 \\
\hline$a_{G}\left(t_{0}=40\right)$ & 0.58 & 1.04 & 0.50 & 0.58 \\
$a_{G}(t=400)$ & 4.34 & 5.44 & 2.57 & 2.89 \\
$a_{G+Q}\left(t_{0}=40\right)$ & 3.53 & 4.67 & 2.68 & 2.80 \\
$a_{G+Q}(t=400)$ & 5.88 & 6.80 & 3.73 & 3.96 \\
\hline
\end{tabular}

Table 10 Experimentally measured deflections for series “E” beams.

\begin{tabular}{lllll}
\hline \multirow{2}{*}{ Level of actions } & \multicolumn{4}{c}{ Deflection $(\mathrm{mm})$} \\
\cline { 2 - 5 } & E1-C30/37 & E2-C30/37 & E3-C60/75 & E4-C60/75 \\
\hline$a_{G}\left(t_{0}=40\right)$ & 0.86 & 0.64 & 0.47 & 0.46 \\
$a_{G}(t=400)$ & 5.28 & 5.02 & 2.76 & 2.91 \\
$a_{G+Q}\left(t_{0}=40\right)$ & 4.46 & 4.06 & 2.37 & 2.39 \\
$a_{G+Q}(t=400)$ & 6.77 & 6.54 & 3.88 & 4.08 \\
\hline
\end{tabular}




\section{Analytical Results}

For analytical analysis of the experiment data first evaluation of autogenous shrinkage, drying shrinkage and creep strains were performed using B3 Model [8]. This analysis provide data to define improved B3 model compliance function $\mathrm{J}\left(t, t^{\prime}\right)$, aging coefficient $\chi$ $\left(t, t^{\prime}\right)$ and relaxation function $\mathrm{R}\left(t, t^{\prime}\right)$. Previously mentioned parameters were used to calculate and to verify long-term deflections by AAEM method. To calculate effects from variable action on long-term deflections of concrete elements quasi-permanent load procedure and the principle of superposition were used.

The analysis of the results, according to quasi-permanent load procedure, was performed to obtain time-dependant deflections under action of variable loads for the series of beams " $D$ " and " $E$ ".

The simplest solution of the problem was taking into consideration one load, as sum of permanent and quasi-permanent load, from which we can obtain initial and time-dependant deflection. This solution can be written with the following equation [9]:

$$
a_{t, \text { exp }}(G+Q)=a_{0}\left(G+\psi_{2} Q\right)+a_{t}\left(G+\psi_{2} Q\right)
$$

where, $a_{t, \text { exp }}(G+Q)$ - experimentally obtained deflection under the effect of long-term permanent load $G$ and repeated variable load $Q ; a_{0}(G+$ $\psi_{2} Q$ ) - analytically obtained initial deflection under the effect of long-term permanent load $\mathrm{G}$ and quasi-permanent load $\psi_{2} Q ; a_{t}\left(G+\psi_{2} Q\right)$-analytically obtained time-dependant deflection under the effect of long-term permanent load $G$ and quasi-permanent load $\psi_{2} Q$, which represents part of the variable load.

This solution has one imperfection in calculation of initial deflection, which for the real loading history used in the experiment, is not correct.

\subsection{Analytical Analysis by the Model B3}

Model B3 was developed by Bazant and Baweja [8] and it is restricted to the service range up to about $0.45 f_{c}$, where, $f_{c}$ is compressive strength of cylinder at age of 28 days.
Prediction of material properties strength and mix-design were restricted to use of Portland cement concrete with following parameters [8]:

$$
\begin{aligned}
& 0.35 \leq w / c \leq 0.85 \\
& 2.5 \leq a / c \leq 13.5 \\
& 160 \leq c \leq 720 \mathrm{~kg} / \mathrm{m}^{3} \\
& 17 \mathrm{MPa} \leq f_{c} \leq 70 \mathrm{MPa}
\end{aligned}
$$

where, $w / c$ is water-cement ratio, $a / c$ is aggregate-cement ratio by weight, $c$ is cement content in $\mathrm{kg} / \mathrm{m}^{3}, f_{c}$ is cylinder compressive strength at age of 28 days.

In the model, calculation of strains at constant stress applied at age of the concrete $t^{\prime}$ can be calculated according to the following equation [8]:

$$
\varepsilon(t)=J\left(t, t^{\prime}\right) \sigma+\varepsilon_{s h}(t)+\alpha \Delta T(t)
$$

where, $J\left(t, t^{\prime}\right)$ is compliance function equal to the strain (elastic and creep strain) at time $t$ caused by a unit uniaxial constant stress applied at age $t^{\prime}, \sigma$ is uniaxial stress, $\varepsilon$ is strain, $\varepsilon_{s h}$ is shrinkage strain, $\Delta T(t)$ is temperature change from reference temperature at age $t$, $\alpha$ is thermal expansion coefficient.

The compliance function further is decomposed on [8]:

$$
J\left(t, t^{\prime}\right)=q_{1}+C_{0}\left(t, t^{\prime}\right)+C_{d}\left(t, t^{\prime}, t_{0}\right)
$$

where, $q_{1}$ is instantaneous initial strain due to unit stress, $C_{0}\left(t, t^{\prime}\right)$ is compliance function for basic creep (creep at constant moisture content and no moisture movement through the material), $C_{d}\left(t, t^{\prime}, t_{0}\right)$ is additional compliance function for creep due to simultaneous drying.

The creep coefficient $\phi\left(t, t^{\prime}\right)$ which represents most convenient method for to introduce creep into structural analysis should be calculated from compliance [8]:

$$
\phi\left(t, t^{\prime}\right)=E\left(t^{\prime}\right) J\left(t, t^{\prime}\right)-1
$$

where, $E\left(t^{\prime}\right)$ is static modulus of elasticity loading age $t^{\prime}$.

Model B3 allows updating of creep prediction on the basis of short-term measurements of creep defining two update parameter $p_{1}$ and $p_{2}$ as follows [8]:

$$
J\left(t, t^{\prime}\right)=q_{1} \cdot p_{1}+p_{2} \cdot F\left(t, t^{\prime}\right)
$$




$$
F\left(t, t^{\prime}\right)=C_{0}\left(t, t^{\prime}\right)+C_{d}\left(t, t^{\prime}, t_{0}\right)
$$

Updating parameters were calculated according to normal equations of at least square linear regression [8]:

$$
\begin{gathered}
p_{2}=\frac{n \sum\left(F_{i} \cdot J_{i}\right)-\left(\sum F_{i}\right) \cdot\left(J_{i}\right)}{n \sum\left(F_{i}^{2}\right)-\left(\sum F_{i}\right)^{2}} \\
p_{1}=\frac{\bar{J}-p_{2} \cdot \bar{F}}{q_{1}}
\end{gathered}
$$

where, $\bar{J}$ is mean of all measured $J_{i}$ values, $\bar{F}$ is mean of all corresponding $F_{i}$ values.

Updating of shrinkage predictions can be also defined on the basis of short-term measurements of shrinkage by parameter $p_{6}$ as follows [8]:

$$
p_{6}=\frac{\sum_{i} \varepsilon_{s h i}^{\prime} \cdot \bar{\varepsilon}_{s h i}}{\sum_{i} \overline{\varepsilon_{s h i}^{2}}}
$$

where, $\bar{\varepsilon}_{s h i}$ is shrinkage values calculated from model B3, $\varepsilon_{s h i}^{\prime}$ is measured short-time values of shrinkage.

The model B3 can be used and for special types of concrete such as high strength concretes. Due to the autogenous shrinkage of the high strength concretes it is necessary total shrinkage to be obtained by following equation [8]:

$$
\varepsilon_{s h}^{\text {total }}\left(t, t_{0}\right)=\varepsilon_{a}(t)+\varepsilon_{s h}\left(t, t_{0}\right)
$$

where, $\varepsilon_{a}$ is autogenous shrinkage strain and $\varepsilon_{s h}$ is drying shrinkage strain.

The value of the autogenous shrinkage strain can be calculated according to the following equation [8]:

$$
\begin{gathered}
\varepsilon_{a}(t)=\varepsilon_{a \infty}\left(0.99-h_{a \infty}\right) S_{a}(t) \\
S_{a}(t)=\tanh \sqrt{\frac{t-t_{s}}{\tau_{a}}}
\end{gathered}
$$

where, $\varepsilon_{a}(t)$ is autogenous shrinkage, $\varepsilon_{a \infty}$ is the final value of autogenous shrinkage, $h_{a \infty}$ is the final self-desiccation humidity (it may be assumed to be $80 \%)$ and $S_{a}(t)$ is time dependence of ultimate autogenous shrinkage.

Experimental results from testing of drying shrinkage, autogenous shrinkage and creep of concrete were analytically verified using Model B3 and updated $\mathrm{B} 3$ on the basis of long-term measurements. Results from the analysis for concrete class $\mathrm{C} 30 / 37$ are given in the following Figs. 7-9.

This analysis using B3 model shows that a good agreement is achieved between the experimental and analytical results especially for the creep compliance. Better results were obtained by using improved B3 model calculating updated parameters $p_{1}$ and $p_{2}$. For concrete class $\mathrm{C} 30 / 37$, on the basis of linear regression, following values were obtained $p_{1}=0.9088$ and $p_{2}=$ 0.998 to adjust the creep compliance (Fig. 7).

Updating of shrinkage predictions was done only by using scaling parameter which for ordinary concrete C30/37 was $p_{6}=0.82$ (Fig. 8).

Analysis of autogenous shrinkage using B3 model shows that proposed formula for autogenous shrinkage predictions is not valid for use neither for ordinary concrete and neither for high-strength concrete. In the analysis of experimental data, it was tried to use the formula proposed for calculation of autogenous shrinkage by the model B3 (Fig. 9).

During the calculation a convergence problem arises when for $t \rightarrow \infty \varepsilon_{a}(t \rightarrow \infty)=\varepsilon_{a \infty}\left(0.99-h_{a \infty}\right)$, because $S_{a}(t) \rightarrow 1$. If $h_{a \infty}=80 \%$, in that case we have $\varepsilon_{a}(t \rightarrow \infty)$ $=0.19 \varepsilon_{a \infty}$ or with other words it does not converge in $\varepsilon_{a}(t \rightarrow \infty)=\varepsilon_{a \infty}[6]$.

Analytical analysis of the autogenous shrinkage was done in accordance to updated formula based on experimental results [6]:

$$
\varepsilon_{a}(t)=\varepsilon_{a \infty}\left(0.99-h_{a \infty}\right)^{\frac{1}{\sqrt{t-t_{s}}}} \cdot S_{a}(t)
$$

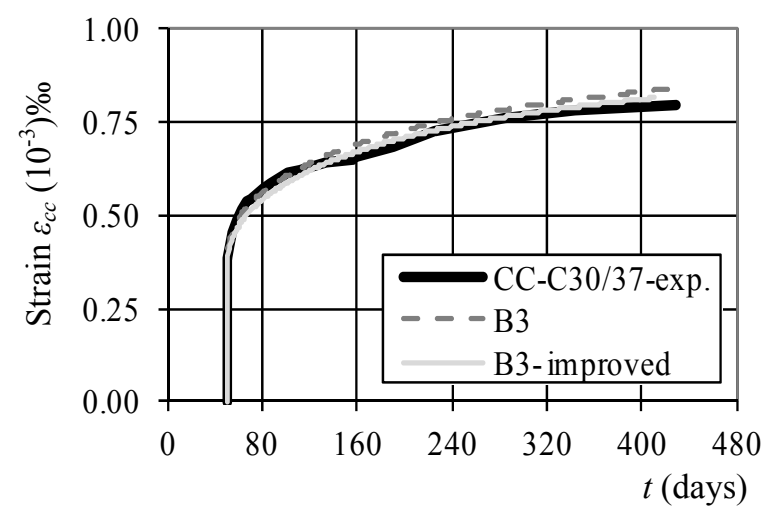

Fig. 7 Diagram creep of concrete-time $\varepsilon_{c c}-t$ for class C30/37: experimental results, B3-model and B3-model improved. 


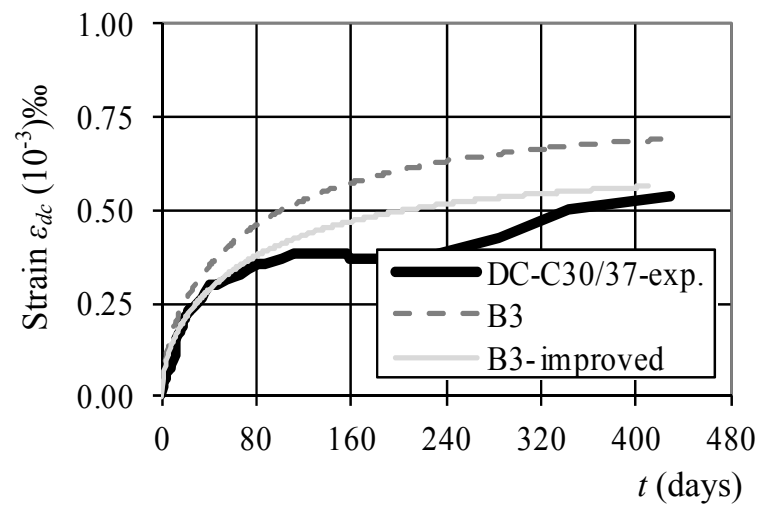

Fig. 8 Diagram drying shrinkage of concrete-time $\varepsilon_{d c}-t$ for class C30/37: experimental results, B3-model and B3-model improved.

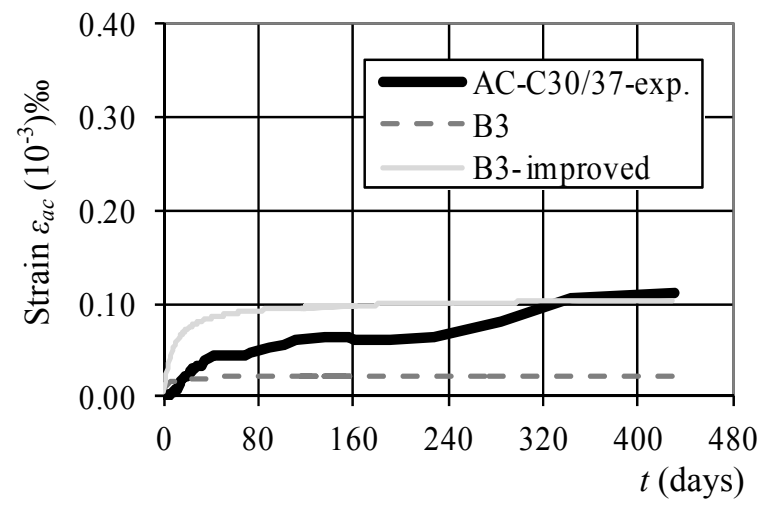

Fig. 9 Diagram autogenous shrinkage of concrete-time $\varepsilon_{a c}-t$ for class C30/37: experimental results, B3-model and B3-model improved.

For high strength concrete $\mathrm{C} 60 / 75$, on the basis of linear regression, $p_{1}=1.4264$ and $p_{2}=0.3319$ were obtained to adjust the creep compliance in B3 model (Fig. 10) and $p_{6}=1.0955$ to adjust drying shrinkage (Fig. 11). Analysis of autogenous shrinkage is given in Fig. 12.

The proposed formula for autogenous shrinkage gives a better approximation for high-strength concrete than for ordinary strength concrete.

\subsection{Analytical Analysis by the AAEM Method}

For both strength classes of concrete, the analysis using model B3 provide necessary information about creep, total shrinkage, aging coefficient and relaxation function as input parameters to carry out further analysis by age adjusting effective modulus method.

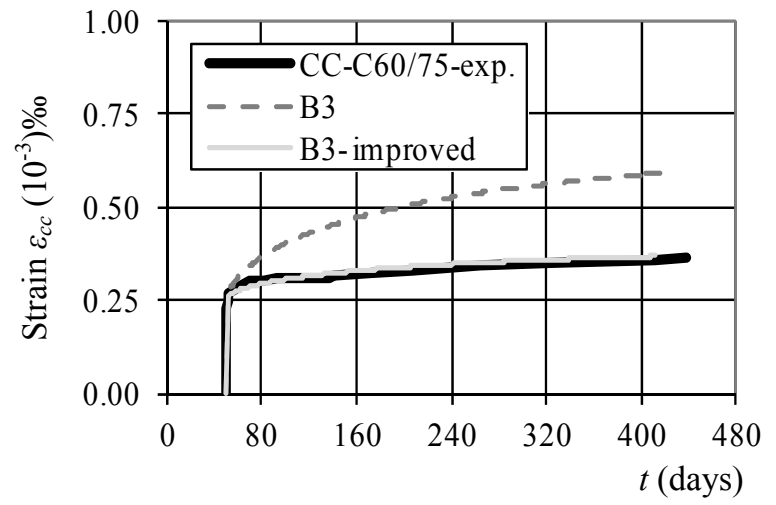

Fig. 10 Diagram creep of concrete-time $\varepsilon_{c c}$-t for class C60/75: experimental results, B3-model and B3-model improved.

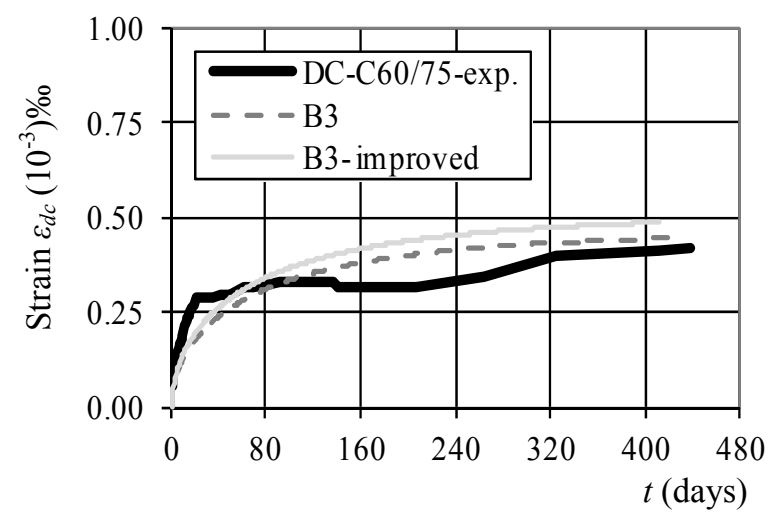

Fig. 11 Diagram drying shrinkage of concrete-time $\varepsilon_{d c}-t$ for class C60/75: experimental results, B3-model and B3-model improved.

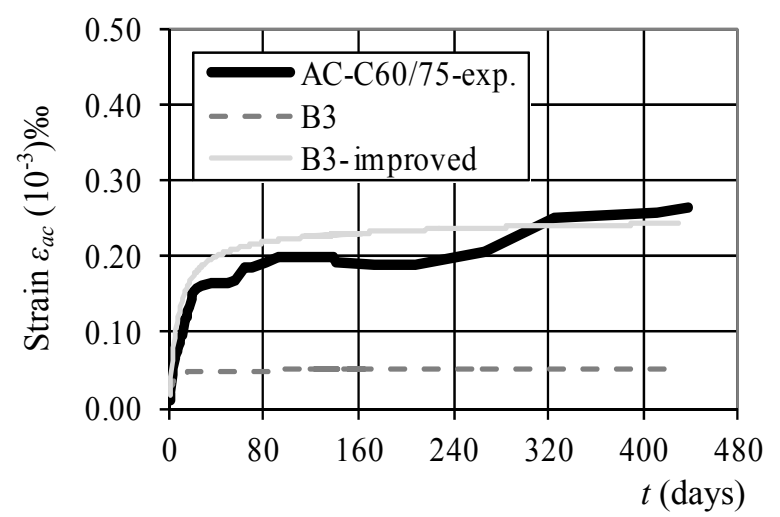

Fig. 12 Diagram autogenous shrinkage of concrete-time $\varepsilon_{a c}{ }^{-t}$ for class C60/75: experimental results, B3-model and B3-model improved.

The age adjusted effective modulus method is formulated for a one step loading history, i.e., for load that is applied in time $t$, which is constant until current 
time $t$ or varies monotonically at a gradually decreasing rate. The response to multi step load histories can be obtained by superposing the solutions for several one-step histories. While the effective modulus method takes one step from the unstressed state of the structure at time $t_{1}{ }^{-}$before the first loading to the current state at time $t$, AAEMM takes one step from the initial stressed state at time $t_{1}{ }^{+}$after application of the load to the current state at time $t$. Hence, the initial state just after the loading, which does not have any importance in the effective modulus method, must be calculated separately, based on the standard elastic analysis of structure on the initial modulus of elasticity $E\left(t_{1}\right)[10]$.

In the AAEM method history of stress and strain between the initial and the current state is approximated by a linear combination of creep at constant stress and relaxation at constant strain. The strain $\alpha$, which is applied in time $t_{l}$ and kept constant, causes stress history $\sigma(t)=\alpha R\left(t, t_{1}\right)$, where, $R$ is a relaxation function. Also, the stress $\beta$, applied in time $t_{1}$ and kept constant causes strain history $\varepsilon(t)=\beta J\left(t, t_{l}\right)$, where, $J$ is the compliance function. In accordance to the principles of superposition the stress and strain histories are [10]:

$$
\begin{gathered}
\varepsilon(t)=\alpha+\beta J\left(t, t_{1}\right) \\
\sigma(t)=\alpha R\left(t, t_{1}\right)+\beta \quad\left(\mathrm{t} \geq \mathrm{t}_{1}\right)
\end{gathered}
$$

Corresponding to each other (i.e., satisfy the viscoelastic constitutive equations). The coefficients $\alpha$ and $\beta$ can be expressed in terms of the stress value $\sigma\left(t_{1}{ }^{+}\right)$ $=\sigma_{l}$, just after the application of the load, and $\sigma(t)=\sigma_{1}$ $+\Delta \sigma$, at time $t$. Substituting these values in (15) and calling that $R\left(t_{1}, t_{1}\right)=1 / J\left(t_{1}, t_{1}\right)=E\left(t_{1}\right)$-elasticity modulus at age $t_{l}$, we obtain two linear equations for $\alpha$ and $\beta[10]$ :

$$
\begin{gathered}
\alpha E\left(t_{1}\right)+\beta=\sigma_{1} \\
\alpha R\left(t, t_{1}\right)+\beta=\sigma_{1}+\Delta \sigma
\end{gathered}
$$

From which is possible to determine the coefficients:

$$
\begin{aligned}
& \alpha=\frac{\Delta \sigma}{R\left(t, t_{1}\right)-E\left(t_{1}\right)} \\
& \beta=\frac{\Delta \sigma E\left(t_{1}\right)}{E\left(t_{1}\right)-R\left(t, t_{1}\right)}+\sigma_{1}
\end{aligned}
$$

With the use of this result the initial (elastic) strain can be obtained from Eq. (14) in:

$$
\varepsilon_{1}=\varepsilon\left(t_{1}^{+}\right)=\alpha+\beta J\left(t_{1}, t_{1}\right)=\alpha+\frac{\beta}{E\left(t_{1}\right)}=\frac{\sigma_{1}}{E\left(t_{1}\right)}
$$

And the strain increment:

$$
\begin{aligned}
& \Delta \varepsilon=\varepsilon(t)-\varepsilon\left(t_{1}^{+}\right)=\beta\left[J\left(t, t_{1}\right)-J\left(t_{1}, t_{1}\right)\right]= \\
& \Delta \sigma \frac{E\left(t_{1}\right) J\left(t, t_{1}\right)-1}{E\left(t_{1}\right)-R\left(t, t_{1}\right)}+\sigma_{1}\left[J\left(t, t_{1}\right)-\frac{1}{E\left(t_{1}\right)}\right]
\end{aligned}
$$

The expression $E\left(t_{1}\right) J\left(t, t_{1}\right)-1$ is a creep coefficient $\varphi\left(t, t_{1}\right)$. If we introduced the so called age adjusted effective modulus [10]:

$$
E^{\prime \prime}\left(t, t_{1}\right)=\frac{E\left(t_{1}\right)-R\left(t, t_{1}\right)}{E\left(t_{1}\right) J\left(t, t_{1}\right)-1}=\frac{E\left(t_{1}\right)-R\left(t, t_{1}\right)}{\varphi\left(t, t_{1}\right)}
$$

And replace $\sigma_{1} / E\left(t_{1}\right)$ by $\varepsilon_{1}$ in accordance to Eqs. (20) and (21) assumes a convenient form:

$$
\Delta \varepsilon=\frac{\Delta \sigma}{E^{\prime \prime}\left(t, t_{1}\right)}+\varepsilon_{1} \varphi\left(t, t_{1}\right)
$$

This is the basic equation of the AAEM method in which the increment of strain increase over the interval $\left(t_{1}, t\right)$ is equal to the increment of stress divided by the effective modulus plus the initial (elastic) strain multiplied by the creep coefficient.

To keep the previous derivation simple, we have neglected the shrinkage effect. Anyway the shrinkage effect can be automatically incorporated by replacing of $\varepsilon(t)$ with the mechanical strain:

$$
\varepsilon(o t)=\varepsilon(t)-\varepsilon_{s h}(t)
$$

which means that the increment of shrinkage strain must be added to the right side of the Eq. (23). The final form of the basic equation of AAEM (in case of uniaxial stress) is Ref. [10]:

$$
\begin{gathered}
\Delta \varepsilon(t)=\frac{\Delta \sigma(t)}{E^{\prime \prime}\left(t, t_{1}\right)}+\varepsilon\left(t_{1}^{+}\right) \varphi\left(t, t_{1}\right)+\Delta \varepsilon_{s h}(t) \\
\varepsilon\left(t_{1}^{+}\right)=\frac{\sigma\left(t_{1}^{+}\right)}{E\left(t_{1}\right)}
\end{gathered}
$$

where:

$$
\begin{aligned}
& \Delta \varepsilon(t)=\varepsilon(t)-\varepsilon\left(t_{1}^{+}\right), \\
& \Delta \sigma(t)=\sigma(t)-\sigma\left(t_{1}^{+}\right), \\
& \Delta \varepsilon_{s h}(t)=\varepsilon_{s h}(t)-\varepsilon_{s h}\left(t_{1}\right)
\end{aligned}
$$

For simple use, the age adjusted effective modulus, whose primary definition is the Eq. (22) can be 
expressed in the following form [10]:

$$
E^{\prime \prime}\left(t, t_{1}\right)=\frac{E\left(t_{1}\right)}{1+\chi\left(t, t_{1}\right) \varphi\left(t, t_{1}\right)}
$$

which represents a adjustment of the effective modulus. This equation has advantage because the so called aging coefficient [10]:

$$
\chi\left(t, t_{1}\right)=\frac{E\left(t_{1}\right)}{E\left(t_{1}\right)-R\left(t, t_{1}\right)}-\frac{1}{\varphi\left(t, t_{1}\right)}
$$

$\chi\left(t, t_{1}\right)$ varies relatively little, usually from 0.5 to 1.0 with 0.8 as most typical value. Using AAEM method, effects from variable actions were calculated to obtain the long-term deflection using quasi-permanent combinations of actions defining factor $\psi_{2}$.

On the following Figs. 13 and 14 diagrams long-term deflections vs. time are given for the beams of concrete class C30/37. Long-term behavior of high-strength concrete beams concrete class C60/75 is given in Fig. 15.

Results are given on the basis of experimental data and analytical results by AAEM method for the development of deflections during time using data from previous analysis by the B3 model and the improved B3 model.

According to the analysis presented within the Figs. 13-15, best results were obtained when quasi-permanent coefficient was set by the factor $\psi_{2}=$ 0.49 for concrete beams class C30/37 and $\psi_{2}=1.0$ for concrete beams class C60/75. This means that, in the specific beam set tested, approximately $50 \%$ of the

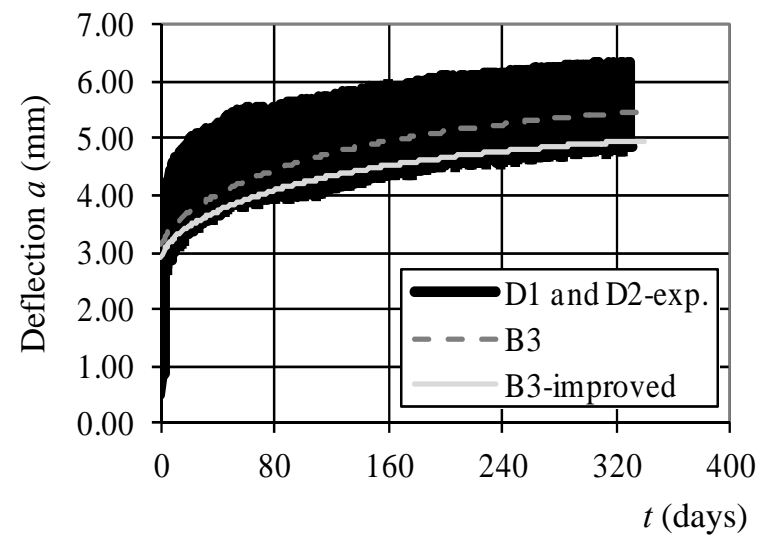

Fig. 13 Diagram deflection-time $a-t$ for series $D$ beams concrete class $\mathbf{C} 30 / 37$.

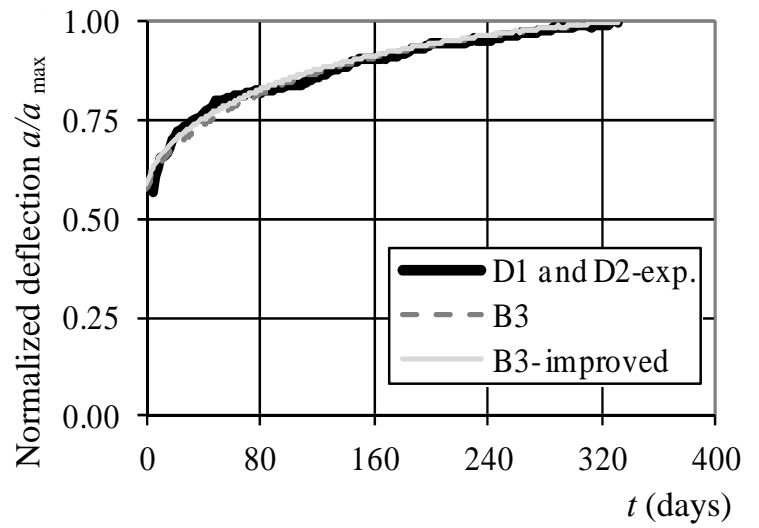

Fig. 14 Diagram normalized deflection-time $a / a_{m a x}-t$ for series D beams concrete class C30/37.

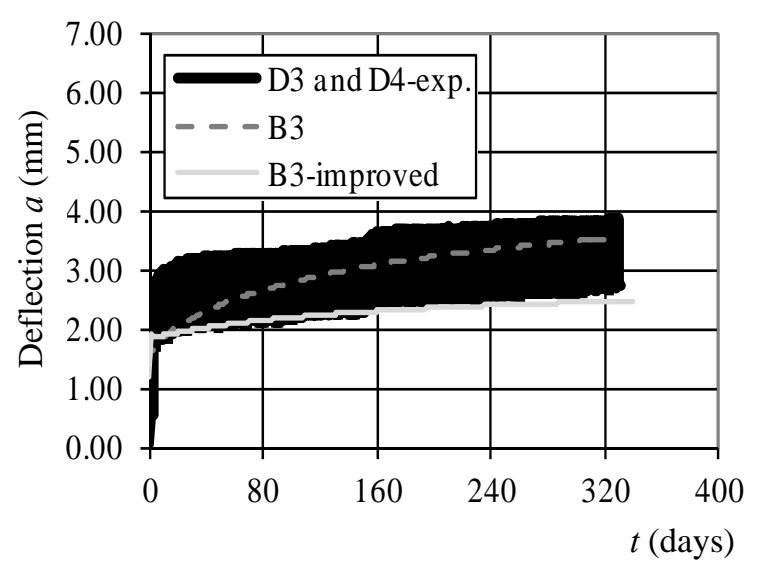

Fig. 15 Diagram deflection-time $a-t$ for series D beams concrete class $\mathrm{C60} / 75$.

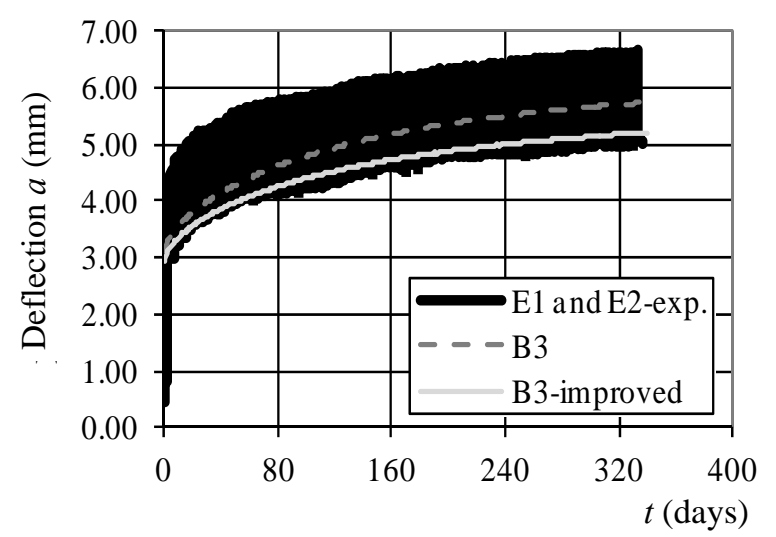

Fig. 16 Diagram deflection-time a-t for series $\mathrm{E}$ beams concrete class $\mathrm{C} 30 / 37$.

variable load should be taken as quasi-permanent load for ordinary concrete beams and full value of variable loads for high-strength beams.

For series "E" beams casted by concrete class C30/37 according to the diagrams presented in Figs. 16 


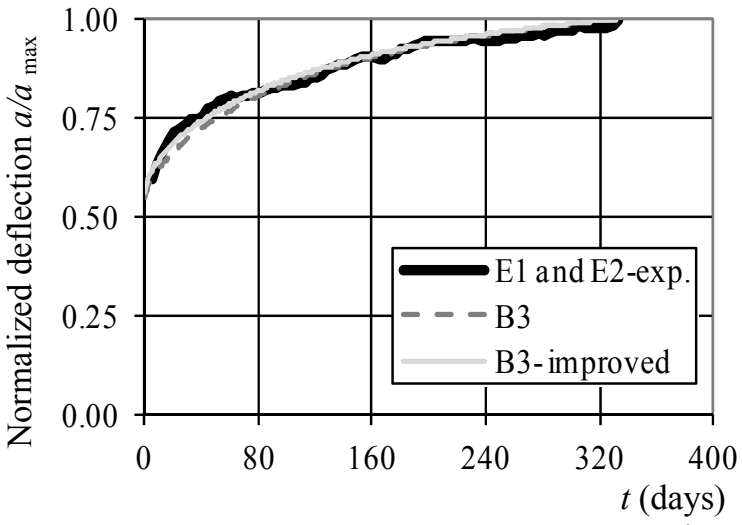

Fig. 17 Diagram normalized deflection-time $a / a_{\max }-t$ for series $\mathrm{E}$ beams concrete class $\mathrm{C} 30 / 37$.

and 17 best results were obtained when the quasi-permanent coefficient was set to $\psi_{2}=0.66$.

In the series "D" and "E" with beams made of high-strength concrete, the analysis of the experimental results and the results obtained with the analytical AAEM method analysis shows that for the determination of the coefficients $\psi_{2}$ the stress state should be included in the analysis when cracks appears.

The chosen loading histories for these series of high-strength concrete beams were determined in order to compare the behavior with reinforced concrete beams made of ordinary concrete.

But higher mechanical properties of high-strength concrete enable cracks appearance practically at the level of service load. At this level due to the approximately equal cracking moment $M_{c r}=11.6 \mathrm{kNm}$ and moment of the service loads $M_{s}=12.6 \mathrm{kNm}$, a stabilized state of cracks was formed. Thus, the coefficient of participation for defining of the variable load as a quasi-permanent action is approaching to $\psi_{2}=$ 1 in the analytical solution in order to obtain the experimentally measured deflections. However, this does not coincide with usual practical cases. In this way replacing variable load by permanent load to calculate time-dependant deflections for elements made of high-strength concrete results in wrong solutions.

For the elements of high-strength concrete, it is necessary to define higher values of the stresses, i.e., state of stress that causes cracks from the action of load less than the value of service load. This is a prerequisite for proper analysis of variable loads effect on the behavior of the reinforced high-strength concrete elements to obtained values for the quasi-permanent coefficient $\psi_{2}$. Generally, a decision must be made between cracked and uncracked sections.

\section{Conclusions}

From the experimental and analytical analyses of long-term behavior of reinforced concrete beams, made of ordinary and high-strength concrete, subjected to long-term permanent load and repeated variable load following notes are concluded:

- Actions of long-term permanent load and repeated variable load have significant influence on the long-term behavior of concrete beams made of ordinary and high-strength concrete;

- Long-term behavior of concrete elements under action of long-term permanent load and repeated variable load depends on the loading history, i.e., especially on the cycles of loading/unloading by variable load $\left(\Delta t_{1}=24 \mathrm{~h} ; \Delta t_{2}=48 \mathrm{~h}\right)$;

- Analytical analysis of drying shrinkage and creep using B3 model shows good agreement with experimental results using updated parameters for improved estimations;

- On the basis of regression analysis, for ordinary concrete values of creep update parameters $p_{1}$ and $p_{2}$ and shrinkage update parameter $p_{6}$ were obtained;

- These $p_{1}, p_{2}$ and $p_{6}$ values for high-strength concrete are employed to adjust creep compliance and drying shrinkage strain;

- Analysis of autogenous shrinkage strain according to B3 model results in inaccurate estimations of strains hence, new formula-Eq. (13) was proposed to obtain analytical solution using experimental results;

- Using age adjusted effective modulus method and principle of superposition analysis quasi-permanent factor $\psi_{2}$ were obtained to determine the influence of variable load on the long-term behavior of concrete for control of the deflections. 
According to experimental and analytical results, repeated variable action was replaced by quasi-permanent action defining it through the quasi-permanent factor $\psi_{2}$.

For the concrete class C30/37 and considered beam arrangements and loading histories by repeated variable actions factor $\psi_{2}=0.49 \approx 0.50$ was obtained for cycles of loading/unloading $\Delta t=24 \mathrm{~h}$.

Additionally factor $\psi_{2}=0.66 \approx 0.65$ was determined for cycles of loading/unloading $\Delta t=48 \mathrm{~h}$ for beams made of ordinary concrete class $\mathrm{C} 30 / 37$.

For the same loading histories of high strength concrete beams class $\mathrm{C} 60 / 75$ factor $\psi_{2}=1$ was gained.

\section{Acknowledgments}

The first author would like to express his gratitude and compliments to Ruhr-University of Bochum, Germany, to the DAAD (Deutscher Akademischer Austausch Dienst) and SEEFORM Ph.D. studies for the scholarship and the financial support, during the work on Ph.D. thesis.

\section{References}

[1] L. Zongjin, C. Leung, Y. Xi, Structural Renovation in Concrete, Taylor \& Francis, Abingdon, 2009.

[2] CEB-Comité Euro-International du Béton Bulletin d'information $\mathrm{N}^{\mathrm{o}} 235$, Serviceability Models-Behaviour and Modeling in Serviceability Limit States Including Repeated and Sustained Loads, in: G. Balazs (Ed.), Lausanne, 1997.P.C. Aitcin, High-Performance Concrete, E\&FN SPON, London, 1998.

[3] H. Gulvanessian, J.A. Calgaro, M. Holicky, Designers' Guide to EN 1990 Eurocode: Basis of Structural Design, Thomas Telford, London, 2002.

[4] M. Zink, C.A. Graubner, A. Garg, 2003 Edition of DIN Report 102 Concrete Bridges, TU Darmstadt, Darmstadt: 2002.

[5] R. Syrja, Eurocodes: Loading Bridges, Bridge Engineering, Helsinki University of Technology (HUT), Helsinki, 2003.

[6] T. Arangelovski, Time-dependent behavior of rein-forced high-strength concrete elements under action of variable loads, Doctoral Dissertation, University St. Cyril and Methodius, Skopje, 2010.

[7] E. Tazawa, Autogenous Shrinkage of Concrete, in: Proceedings of the International Workshop Organized by JCI (Japan Concrete Institute), Hiroshima, June 13-14, 1998.

[8] Z.P. Bazant, S. Baweja, Creep and shrink age prediction model for analysis and design of concrete structures: Model B3, in: The Adam Neville Symposium: Creep and Shrinkage-Structural Design Effects, SP-194, American Concrete Institute 2000, Farmington Hills, ACI, 2000.

[9] G. Markovski, Influence of variable loads to time-dependant behavior of prestressed concrete elements, Doctoral Dissertation, University St. Cyril and Methodius, Skopje, 2003.

[10] M. Jirasek, Z.P. Bazant, Inelastic Analyses of Structures, John Wiley \& Sons, London, 2001. 